\title{
Histopatologia em pulmões e corações de frangos suplementados com oxigênio durante a fase de incubação
}

\author{
Histopathology of broiler chicken lungs and hearts supplemented with \\ oxygen during the hatchery period
}

\author{
Fátima Regina Ferreira Jaenisch ${ }^{1}$ Vilmar Cucchi $^{2}$ Gary Bitencourt ${ }^{3}$ \\ Waldomiro Barioni Júnior ${ }^{4}$ Ricardo Alfredo Soncini $^{5}$
}

\section{RESUMO}

Analisou-se histopatológicamente, o efeito da suplementação de dois por cento (2\%) de oxigênio nas máquinas de incubação, durante o período embrionário, sobre corações $e$ pulmões de aves no primeiro e no $40^{\circ}$ dia de vida. A descrição das alterações histológicas dos órgãos revelou que as aves que receberam a suplementação apresentaram menores graus de lesões nos tecidos estudados e redução da taxa de mortalidade dos frangos.

Palavras-chave: análise histopatológica, coração, pulmão, frangos de corte, suplementação de oxigênio, incubação de ovos.

\section{ABSTRACT}

Histopathological analysis of broiler chicken lungs and hearts were made to determine the effect of $2 \%$ oxygen supplementation during the hatchery period on the first and the 40th days of ages. The histopathological description response of the heart and lung indicated that oxygen supplementation during egg incubation, carried out in this work, resulted in less severe changes in chick's organs and reduction of the mortality rates.

Key words: histopathology analysis, hearth, lung, broiler, oxygen supplementation.

\section{INTRODUÇÃO}

As linhagens comerciais de frangos de corte são bastante sensíveis à deficiente oxigenação tecidual (hipóxia). Essa predisposição, nos frangos, é determinada pelo rápido crescimento corporal dessas aves que exige grande esforço metabólico e conseqüentemente maior demanda de oxigeno tecidual (JULIAN, 1993; JAENISCH et al., 2001). Todas as condições que reduzem o aporte de oxigênio ou que aumentem a demanda desse nos tecidos, causam hipertensão pulmonar, sendo essa a causa mais freqüente de falhas cardíacas em frangos tipo "griller" (COELLO, 1993; ENKVETCHAKUL et al., 1995; MAXWELL \& ROBERTSON, 1997).

A embriogênese também é um processo fisiológico sensível à hipóxia e o desenvolvimento embrionário depende da perfeita sincronização dos fatores que compõem a incubação artificial de ovos. Durante esse período, as trocas gasosas, especialmente a oxigenação sangüínea no embrião, são realizadas por meio de centenas de poros existentes na casca dos ovos das aves (GONÇALVES, 1994). A partir do momento em que o pinto bica a câmara de ar, a oxigenação que até então era feita pela membrana coreo-alantóide passa a ser realizada gradativamente, pelos pulmões (TULLET, 1990). Proporcionalmente ao aumento da taxa de ganho de peso, nas linhagens de frangos, também a embriogênese dessas aves sofreu modificações e o tempo necessário para a incubação dos ovos foi reduzido de 24 horas nas últimas duas

\footnotetext{
${ }^{1}$ Médico Veterinário, MSc, Pesquisador Embrapa Suínos e Aves, CP 21, 89700-000, Concórdia, SC, Brasil. E-mail: fatima@cnpsa.embrapa.com.br

${ }^{2}$ Sadia Concórdia SA, Concórdia, SC, Brasil. Bacharel em Administração.

${ }^{3}$ Médico Veterinário, White Martins Gases SA, Chapecó, SC, Brasil.

${ }^{4}$ Estatístico, MSc, Pesquisador Embrapa Suínos e Aves, Brasil.

${ }^{5}$ Médico Veterinário, Sadia Concórdia SA, Concórdia, SC, Brasil.
} 
décadas e, conseqüentemente, a exigência de oxigenação durante o período embrionário foi alterada (COLEMAN \& COLEMAN, 1992). Trabalhos realizados por MAXWELL (1990) e BAGLEY \& CRISTENSEN (1991) relataram que embriões sujeitos à hipóxia apresentaram lesões pulmonares e cardíacas precoces, que aceleraram a manifestação de problemas metabólicos como a ascite e morte súbita.

Durante as fases de cria e terminação, os frangos de linhagens de crescimento rápido sofrem alterações do metabolismo basal, exacerbado por fatores ambientais e nutricionais tais como: temperaturas inadequadas (JAENISCH et al., 2001), ventilação deficiente dietas com altas densidades nutricionais (CALNECK, et al., 1997; COELLO \& AVILA, 2001). Esses fatores determinam excessiva demanda fisiológica, especialmente sobre o sistema cardio-respiratório da ave, desencadeando o processo de hipertensão pulmonar e progressivamente de hipóxia sistêmica e celular. O quadro é agravado por aumento da resistência ao fluxo sangüíneo no pulmão, desequilíbrio entre necessidade e fornecimento de oxigênio e insuficiência cardíaca que evolui para hipertensão pulmonar (GONZALES \& MACARI, 2000).

A suplementação de oxigênio em máquinas de incubação é uma metodologia que visa aumentar a capacidade pulmonar dos frangos ainda no período embrionário, uma vez que o fortalecimento do sistema cárdio-respiratório em frangos de corte é fator fundamental para a redução de grande parte dos problemas metabólicos, comuns nas atuais linhagens de frangos. Neste trabalho, estão reportadas as alterações histopatológicas observadas ao nascimento e ao abate, nos parênquimas pulmonares e cardíacos de aves que receberam a suplementação de oxigênio e das que não foram suplementadas durante o período embrionário.

\section{MATERIAL E MÉTODOS}

Foram utilizadas duas incubadoras comerciais de estágio múltiplo e dois nascedouros com capacidade para 16.800 ovos, nos quais foram incubados ovos provenientes de matrizes de corte com idade média de 43 semanas de idade.

A suplementação de dois por cento (2\%) de oxigênio na máquina incubadora (A), foi realizada sob orientação técnica da White Martins Gases Industriais S.A., a partir do quinto até o $18^{\circ}$ dia de incubação, totalizando 23\% de oxigênio dentro da máquina (TULLET, 1990). O respectivo nascedouro (A1) para onde foram transferidos os ovos no $18^{\circ}$ dia também foi suplementado de $2 \%$ de oxigênio até o nascimento. Os ovos do grupo controle, não suplementados, foram incubados em outra incubadora (B) e respectivo nascedouro (B1), os quais não receberam a suplementação, permanecendo com a concentração usual de oxigênio (21\%).

O experimento foi realizado pela Embrapa Suínos e Aves. Contou com a colaboração da equipe técnica do incubatório e fomento da Sadia Concórdia SC., sendo a oxigenação das máquinas incubadoras, orientada pela White Martins Gases S.A.

No incubatório, logo após o nascimento e sexagem, sacrificaram-se 40 pintos machos, provenientes dos respectivos nascedouros A1 e B1, dos quais foram coletados fragmentos de coração e pulmão, para exames histopatológicos. Os demais pintos machos foram alojados em quatro aviários com capacidade para 6.000 frangos. Os aviários foram divididos ao centro por cercado de madeira para alojar no mesmo aviário em uma das extremidade, 3.000 pintos que receberam a suplementação de oxigênio e na outra, 3.000 pintos sem o tratamento (grupo controle).

Durante o ciclo de crescimento dos frangos, foram avaliadas as taxas de mortalidades dos lotes. No final do experimento, aos 40 dias de idade, sacrificaram-se 40 frangos por tratamento, analisaramse macroscopicamente as carcaças e coletaram-se corações e pulmões para posterior processamento e avaliação histopatológica.

Os fragmentos de coração e pulmões foram coletados imediatamente após o sacrifício das aves e fixados em formalina $10 \%$. Posteriormente foram recortados, desidratados, clarificados, incluídos em parafina, laminados a cinco micrômetros, corados por hematoxilina-eosina segundo técnica de LUNA (1968), para posterior exame à microscopia óptica.

Os dados qualitativos foram analisados por modelos categorizados seguidos de teste de Quiquadrado e os dados quantitativos por Análise de Variância (SNEDECOR \& COCHRAN,1967).

Imediatamente após o sacrifício das aves procederam-se exames anatomopatológicos analisando-se principalmente corações e pulmões. As alterações macroscópicas nos pulmões foram classificadas em diferentes graus de processos congestivos e no coração pela consistência da musculatura cardíaca em: hipertrofiada, dilatada e flácida.

As lesões histológicas foram classificadas subjetivamente em três grupos (discretas, moderadas e severas), de acordo com o grau de severidade das principais alterações teciduais e codificadas respectivamente por números $(1,2,3)$ conforme a

Ciência Rural, v.35, n.3, mai-jun, 2005. 
extensão das lesões nos fragmentos estudados: 1 . Grau discreto: Alteração comprometendo até $10 \%$ do fragmento examinado. No pulmão presença de pequenos focos de edema e congestão sem comprometimento dos parabrônquios e no coração congestão da musculatura. 2. Grau moderado: Alteração comprometendo até $40 \%$ do fragmento examinado. Fragmento de pulmão apresentando edema, congestão, hiperpalsia celular entre os espaços alveolares e infiltrado celular nos parabrônquios. No coração, presença de congestão e infiltrado celular entre as miofibras. 3. Grau severo: Alteração comprometendo acima de $41 \%$ do fragmento examinado. Fragmento de pulmão apresentando edema, congestão, hemorragia, hiperplasia celular e comprometimento dos parabrônquios. No coração, presença de congestão, na musculatura cardíaca, infiltrado celular e degeneração das miofibras.

\section{RESULTADOS E DISCUSSÃO}

As avaliações realizadas no primeiro dia de idade nos pintos e aos 40 dias nos frangos, constaram de análise anatomopatológica e avaliação histopatológica de coração e pulmões. As mortalidades totais e por ascite foram computadas ao final do experimento. Os exames histológicos mostraram a redução das alterações no parênquima pulmonar e no tecido cardíaco das aves que receberam a suplementação de $2 \%$ de oxigênio durante o período embrionário. Houve associação entre os graus de lesões dos órgãos examinados e os tratamentos, mostrando que havia maior alteração tecidual nos grupos suplementados com $\mathrm{O}_{2}$.

Ao final do experimento, o percentual de mortalidade total no grupo tratado foi reduzido em $1,06 \%$ e da mortalidade por ascite em $0,46 \%$, quando comparado ao obtido no grupo controle, sem a oxigenação suplementar na incubação. A taxa de mortalidade por ascite foi estudada por ser um parâmetro importante para medir a ocorrência de transtornos no sistema cardio-respiratório. O aumento da resistência pulmonar culmina com hipertrofia ventricular direita causando o processo de congestão venosa generalizada e extravasamento de líquido para a cavidade abdominal.

O exame macroscópico dos pintos não mostrou alterações significativas. No entanto, nos frangos, foram observadas lesões pulmonares e cardíacas compatíveis com congestão passiva crônica. Nos pulmões dos frangos, edema e congestão foram as alterações preponderantes, caracterizadas pelo aumento de volume e tumefação do órgão. Essas alterações geralmente estavam associadas à presença de líquido claro no espaço pericárdico, hipertrofia cardíaca direita, flacidez da musculatura do coração e congestão de outros órgãos abdominais, ratificando alterações decorrentes deficiente oxigenação tecidual (MCGOVERN et al., 1999).

Os resultados obtidos nos exames histopatológicos apresentaram correlação entre o tratamento e a incidência de alterações teciduais dos órgão estudados, mostrando que a oxigenação suplementar durante o período embrionário interferiu na estrutura histológica dos órgãos analisados e conferiu maior integridade aos tecidos.

Nos pulmões, a presença de placas condróides foi registrada nos dois tratamentos ocorrendo em $100 \%$ dos frangos não suplementados $(\mathrm{P}<0,05)$. Nos pintos, essas alterações não apresentaram diferenças estatísticas entre os tratamentos $(\mathrm{P}>0,05)$. As placas ou nódulos, consistem em pequenas estruturas hialinas, com células condróides de formato geralmente arredondado, dispersas no parênquima pulmonar (Figura 1).

Dentre as hipóteses quanto a origem desses nódulos condróides, LEVINE \& BATES (1976) sugerem que os fibroblastos poderiam estimular a produção de colágeno durante períodos de hipóxia e a persistência desse quadro resultaria no processo de fibrose. MAXWELL et al. (1988) reportam que aves mantidas em condições de ventilação inadequadas desenvolvem fibrose no parênquima pulmonar aumentando o número dessas placas, sendo esse um achado histopatológico freqüente nos pulmões de aves com hipertensão pulmonar.

No parênquima pulmonar, hiperplasia celular nos septos alveolares foi observada em todos os frangos examinados, apresentando-se de forma discreta e moderada com associação entre tratamentos $(\mathrm{P}<0,01)$, abrangendo o parênquima pulmonar e imediações dos parabrônquios. A hiperplasia dos septos alveolares era constituída principalmente por linfócitos, caracterizando um quadro de pneumonia intersticial e congestão (Figura 1). O comprometimento de até $50 \%$ do parênquima pulmonar (grau moderado), ocorreu em 11\% das aves tratadas e em $46 \%$ das não suplementadas, mostrando que a oxigenação reduziu a severidade das alterações. A presença do infiltrado celular poderia ter determinado o espessamento das paredes alveolares, reduzindo a difusão do oxigênio, dificultando as trocas gasosas e conseqüentemente acarretando a perda da capacidade de oxigenação tecidual por colapso da barreira aeromática. Nos pintos, ao primeiro dia de vida, não houve diferença significativa entre os 


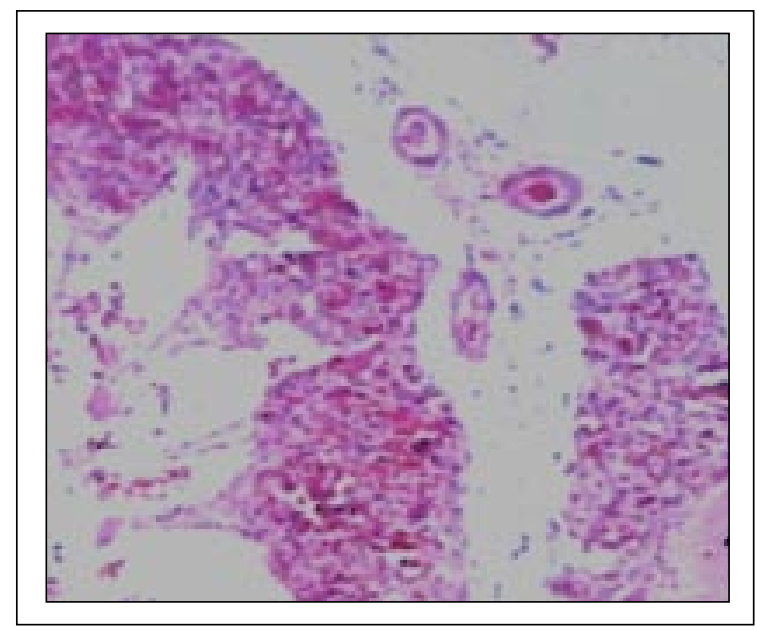

Figura 1 - Pulmão de frango.

1.1. Parênquima pulmonar congesto com hiperplasia celular nos septos alveolares.

1.2. Presença de placa condróide (seta). (H \&E 25x). Foto: Fátima Jaenisch

tratamentos e a incidência de hiperpalsia celular intraalveolar $(\mathrm{P}>0,05)$.

Outro achado histológico importante foi a hipertrofia do músculo liso dos parabrônquios (Figura 2), mostrando associação entre os tratamentos tanto nos pulmões dos pintos ao primeiro dia de vida $(\mathrm{P}<0,01)$ como nos frangos ao abate $(\mathrm{P}<0,05)$.

Nos pintos suplementados, a hipertrofia muscular dos parabrônquios foi diagnosticada como uma lesão de grau discreto em todas as análises histopatológicas. Nos pintos não suplementados, esse achado ocorreu como lesão discreta em $63 \%$ das aves e como moderada em $37 \%$. A constatação da maior intensidade das alterações no grupo não suplementado sugere que, durante a incubação, as aves estavam submetidas à deficiente oxigenação e que a suplementação tenha reduzido essa deficiência. Segundo TULLET (1990), a partir do $18^{\circ}$ dia de incubação, a oxigenação sangüínea passa a ser feita gradativamente pelos pulmões e, nesse período, esforços respiratórios excessivos predisponham à lesões teciduais no embrião.

Nos frangos que receberam oxigenação durante o período embrionário, a hipertrofia muscular dos parabrônquios também foi mais discreta quando comparada ao grupo não suplementado, no qual 14\% dos diagnósticos foram classificados de grau severo. O aumento de volume desses músculos, indica maior esforço pulmonar para compensar a redução da capacidade de trocas de oxigênio em casos de hipoxemia (WILSON et al., 1988).

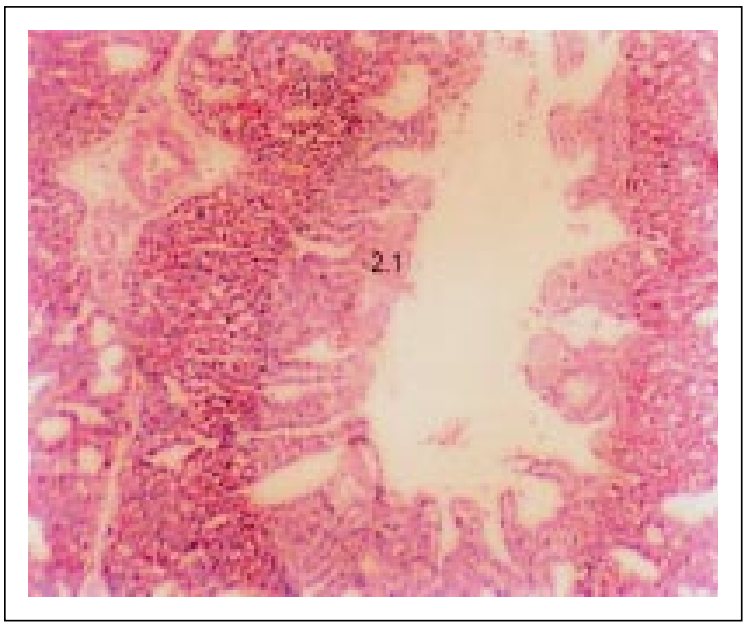

Figura 2 - Pulmão de frango.

2. 1. Hipertrofia dos músculos parabronquiais (H\&E 25x).

Foto: Fátima Jaenisch.

Congestão e edema no parênquima pulmonar foram observados especialmente junto aos parabrônquios, evidenciado pelo acúmulo do sangue em capilares e vênulas. Semelhantes alterações foram descritas por MAXWELL et al., (1987), em aves submetidas à hipóxia. A partir de um processo de hipoxemia, o aumento da pressão hidrostática nos terminais venosos resultaria numa ação contrária à ação da pressão osmótica do sangue levando ao acúmulo de líquido nos tecidos instalando-se congestão e edema. No presente trabalho, houve associação entre os tratamentos e presença de edema pulmonar tanto nos pintos $(\mathrm{P}<0,05)$, como nos frangos $(\mathrm{P}<0,001)$. Nos pintos, edema foi observado nos dois tratamentos porém nas aves tratadas essa alteração ocorreu somente no grau discreto. Em frangos, edema pulmonar foi observado com maior severidade e freqüência (97\%) no grupo de aves que não recebeu a suplementação de oxigênio e não foi observado em $37 \%$, das aves suplementadas. O processo de hipóxia estimula a produção de eritrócitos, acarretando uma policitemia compensatória, aumentando a viscosidade do sangue e comprometendo ainda mais o sistema cárdio-respiratório (FREEMAN 1984; MAXWELL et al., 1990). O trabalho cardíaco é acelerado causando insuficiência do coração e o agravamento do quadro de hipertensão pulmonar (MAXWELL et al.,1987; JULIAN, 1993).

O aumento na resistência vascular pulmonar leva à hipertrofia ventricular e posteriormente congestão venosa sistêmica (WIDMAN, 2001). No coração, as principais lesões descritas ocorreram no

Ciência Rural, v.35, n.3, mai-jun, 2005. 
miocárdio, constituindo-se basicamente por degeneração das miofibras e infiltrado celular.

No miocárdio, foram observadas células com citoplasma globoso entre as miofibras. THOMPSON (1983) refere-se a essa alteração no miocárdio como uma infiltração gordurosa, em substituição a um tecido que atrofiou. Nos pintos do grupo suplementado, essa infiltração não foi observada, sendo diagnosticada em 14\% dos corações examinados no grupo controle $(\mathrm{P}<0,01)$, sugerindo que a suplementação diminuiu o esforço cardíaco. O exame histopatológico do coração dos frangos mostrou que a infiltração de tecido adiposo entre as fibras musculares foi mais freqüente nas aves do grupo não suplementados 99\% que nos suplementados $82 \%$ $(\mathrm{P}<0,01)$. MAXWELL et al., (1990) reportam que aves submetidas à hipóxia apresentaram infiltrado de tecido adiposo principalmente nos casos de degeneração cardíaca severa. Os autores analisaram os tecidos à microscopia eletrônica determinando vacuolização mitocondrial nas miofibras degeneradas.

Especialmente nos frangos não suplementados, observou-se a presença de infiltrado difuso de células predominantemente mononucleares, mostrando uma correlação entre os tratamentos $(\mathrm{P}<0,01)$. Em pintos, a presença desse infiltrado não foi estatisticamente significante entre os tratamentos $(\mathrm{P}>0,05)$.

\section{CONCLUSÕES}

Não obstante a suplementação de oxigênio, alterações histopatológicas compatíveis com as causadas por hipoxemia foram observadas em pulmões e corações das aves em ambos os tratamentos mostrando-se mais evidentes nos frangos não suplementados. Nos pulmões, foi detectada a presença de placas condróides, edema e hiperplasia dos músculos lisos dos parabrônquios. No coração, destacou-se a infiltração de células adiposas e mononucleares entre as miofibras cardíacas no grupo não tratado. A partir das evidências histológicas depreende-se que a suplementação de $2 \%$ de oxigênio durante o período embrionário reduziu o grau de severidade das alterações no parênquima pulmonar e no miocárdio das aves tratadas.

\section{REFERÊNCIAS BIBLIOGRÁFICAS}

BAGLEY, L.G; CHRISTENSEN, V.L. Hatchability, haematological indices, and growth of turkey embryos incubated at high altitude with supplemented oxygen during the first and fourth weeks of incubation. Poultry Science, v.70, p358-365, 1991.
CALNECK, B.W. et al. Diseases of poultry. 10.ed. Ames : Iowa State University, 1997. 929p.

COELLO, C.L. et al. El síndrome en pollos de engorda. In. CONFERÊNCIA APINCO DE CIÊNCIA E TECNOLOGIA AVÍCOLAS, 1993, Santos, SP. Anais... Campinas : APINCO, 1993. p.221-245.

COELLO, C.L.; AVILA, G.E. Técnicas de manejo para reducir la incidencia de la ascitis. Industria Avicola, v.48, p.2025, 2001.

COLEMAN, M.; COLEMAN, G. Detenga ascitis antes del nacimiento. Indústria Avícola, v.39, n.7, p.11-15, 1992.

ENKVETCHAKUL B. et al. Pulmonary arteriole hypertrophy in broilers with pulmonary hypertension syndrome (ascites). Poultry Science, v.74, n.10, p.1677-1682, 1995.

FREEMAN, B.M. Physiology and biochemistry of the domestic fowl. London : Academic, 1984. 434p.

GONÇALVES, J.R. Uso de oxigênio em incubatório. In : CONFERÊNCIA APINCO DE CIÊNCIA E TECNOLOGIA AVÍCOLAS, 1994, Curitiba,PR. Manejo da incubação. Curitiba: APINCO, 1994. p.173-180.

GONZALES, E.; MACARI, M. Enfermidades metabólicas em frangos de corte. In: BERCHIERI. JÚNIOR, A.; MACARI, M. Doença das aves. Campinas : Facta, 2000. p.451-481.

JAENISCH, F.R.F. et al. Síndrome da hipertensão pulmonar: a ascite em frangos de corte. Concórdia : EMBRAPA Suínos e Aves, 2001. p.16. (Circular Técnica n. 27).

JUlian, R.J. Ascitis in poultry. Avian Pathology, v.22, p.419-454, 1993.

LEVINE, C.I.; BATES, C.J. The effect of hypoxia on collagen synthesis in cultured the fibroblasts and its relationship to the mode of action of ascorbate. Biochimica et Biophysica, v.444, p.446-452, 1976.

LUNA, L.G. Manual of histologicstaining methods of the Armed Forces Institute of Pathology. 3.ed. New York : McGraw/Hill, 1968. 258p.

MAXWELL, M.H. et al. Hematological and morphological changes in young broiler chicks with experimentally induce hypoxia. Research in Veterinary Science, v.43, p.331-338, 1987.

MAXWELL, M.H. et al. The incidence of ectopic cartilaginous and osseous lung nodules in young broiler fowls with ascites and various other diseases. Avian Pathology, v.17, p.487-493, 1988.

MAXWELL, M.H. et al. Hematological and morphological responses of broiler chicks to hypoxia. Avian Pathology, v.19, p.23-40, 1990.

MAXWELL, M.H.; ROBERTSON, G.W. Vision panorámica de la ascitis en pollos en el mundo: 1996. Industria Avicola, v.44, p.14-25, 1997.

MCGOVERN, R.H. et al. Analysis of right ventricular areas to assess the severity of ascites syndrome in broilers chicken. Poultry Science, v.78, p.62-65, 1999. 
SNEDECOR, G.M; COCCHRAN, W.G. Statistical methods. 6.ed. Ames : Yowa State University, 1967. 593p.

THOMPSON, R.G. Patologia geral veterinária.

Rio de Janeiro: Guanabara Koogan, 1983. $412 \mathrm{p}$.

TULLET, S.G. Science and the art of incubation. Poultry
Science, v.69, p.1-15, 1990.

WIDMAN, R.F. Pathophysiology of heart/lung disorders: pulmonary hypertension syndrome in broiler. World's Poultry Science Journal, v.57, p.289-307, 2001.

WILSON, J.B. et al. Lesions of right failure and ascites in broiler chickens. Avian Diseases, v.32, p.246-261, 1988. 